\title{
An Approach to Smart Study using Pen and Paper Learning
}

\author{
https://doi.org/10.3991/ijet.v12i05.6798 \\ Ahmad Tasnim Siddiqui \\ Taif University, Taif, Saudi Arabia \\ ahmad.tasnimetu.edu.sa \\ Mohd. Muntjir \\ Taif University, Taif, Saudi Arabia \\ muntjir.metu.edu.sa
}

\begin{abstract}
With the emergence of new technologies the area of education is also growing very fast. By using new innovations teaching and learning has become technically very strong. Learning is becoming tech learning or e-learning. Educators and students are getting very smart and hence study and learning is also becoming smart. Maximum available learning systems don't involve pen and paper based learning. Due to the emergence of ICTs in the learning atmosphere it doesn't indicate that our traditional education methodologies have become outdated. Smart study is such a stage which allows students continue to learn in smart way by using smart pens and papers. Using smart paper and pen the contents written on the paper can be converted into digital format. Smart study using pen and paper is helpful for practicing handwriting in same traditional manner. This paper presents a smart study platform which combines work with printed and digital contents.
\end{abstract}

Keywords-E-Learning, digital contents, smart pen, smart paper, learning management

\section{Introduction}

Last few years of ICT (Information and Communication Technologies) has been very innovative and had great impact on our daily life routine. Due the emergence of innovative smart phones, tablets, e-readers and other devices there is a question whether paper and pen are still has some use. Any information written on a piece of paper is static, but when it is being projected on a screen it becomes much more dynamic. The application of ICTs in the field of education has seen a huge transformation. These days paperless working style is on demand and is presenting a realistic picture. Most of the schools, colleges and universities are moving along with this approach by using smart phones, laptops, tablets, and other devices for teaching and learning purposes. 
Due to the advancement in educational system and digitization we are losing the traditional way of reading and writing. It's almost disappearing. Most of the students and teachers don't write with pen, instead they are using writing sticks or simply using keyboards. We observed this problem and with our further study we got an idea to integrate traditional way of reading and writing along with the modern days advanced technologies to get the new way of learning system. In this way we are making traditional way of reading and writing alive. This will also help to improve the writing style of our children as well as the students. Overall we can get some good handwriting. For this purpose we are using smart pens and smart papers for reading and writing. Smart Study system provides an e-learning platform which uses a smart pen and smart paper for writing, reading and combining this with a laptops, smart phones and tablet etc. to produce digital contents and information. This system supports students and children to read, write, solve class room problems and at the same time they are also improving their writing skills. This smart pen writes in same manner like we write with a normal pen but the important feature of the pen is that we can record and store everything written on smart paper. Smart pen converts the words written on smart paper into action. Whatever is written can be converted into text and transferred into PCs, Smart Phones and tablets etc. Smart pen contains a tiny infra-red digital camera just near to the pressure tip of the pen. The digital camera is activated every time you write down on smart paper. It has built-in character recognition feature. Livescribe and Sky Wifi are the leading manufacturers of smart pen and smart paper.

\section{Literature Review}

The recent development in communication and technology brought a wide range of new applications which are developed to support many areas of education and learning. A Pen-based Computing or Pen Computing simply refers to a user-interface (UI) which works by using a pen, rather than traditional input devices such as a mouse or keyboard [14].

According to Ana Belén Lago Vilariño and Iván Pretel García, an e-learning platform that combines work with printed and digital documents. It integrates pen-andpaper-based interaction techniques that enable users to manage their digitized documents. In addition, this platform integrates different e-learning platforms providing a single intuitive interface to manage them [13].

LeapFrog [1], provides LeapReader which is a digital pen for the children aged between 4 to8 that sounds out words, guides letter strokes, and helps them to build understand. Previously, the company created the Fly digital pen, it was a pen very similar to the Livescribe pen, but in the year of 2009 the company discontinued both the support and manufacturing of this pen.

Benlloch, et. al (2009), with their Classroom Presenter, discussed an approach which was a six steps based on a teaching system that provides active teaching and learning techniques and at the same time supports in class faculty/student and student/student collaboration. They implemented the method in first-year Computer 
Engineering Course, using a wireless classroom which was equipped with 25 Tablet PCs for students and one Tablet PC for the faculty or instructor. This was connected to the data projector. Benlloch et. al (2009) proposed the system to gather formative data and in turn they were producing immediate feedback, activities by using Classroom Presenter [15].

Researchers have investigated the use of a smart pen to enhance teaching and learning. In [2], pen-based writing and reading in combination with groupware was used to assist interaction with computer science studies. However, there were no smart pen and paper but was a tablet and styluses were used for the writing.

Miura et al. had performed a number of researches using the digital pen in a classroom [3-5]. In 2005, they were able to develop AirTransNote [3], a learning system which uses digital pen based on an ultrasonic digital pen (Inklink) and PDAs which were used to pass on the student's notes from Inklink to the faculties PC by using wireless LAN. Later [5], an enhanced and reliable system was provided using an Anoto-based digital pen. The system was responsible to examine the activities in class and also monitoring the motivation of children when they were using it to write their notes, calculations and while drawings. According to the result produced by the research most of the children were more and more concentrated, motivated and were enjoying the lectures.

Sellen and Harper (2003) [6] widely discussed advantages and disadvantages of a paperless working. Although, technology has improved a lot but some of the points given by them are still valid. (i) A large number of people still like the traditional way of reading and writing. They just pick the paper and start reading or they can just use the pen to write. An electronic device doesn't provide the same feel while reading and writing [8]. (ii) An electronic device is always dependent on a power supply to start working. While paper does not require any power supply. There is possibility that pen could run out of ink, but this is a very low-cost replacement. (iii) Still the most commonly used method for information retrieval and exchange is the physical paper. These days' computers and PC's are on almost every desk, but a lot of papers are still being used. (iv) The speed of scrolling on physical paper is much faster than the scrolling on PC's. But the main advantages of digital contents are in searching or jumping to the next page.

Besides all the advantages and disadvantages, we want to add some additional words in favor of smart pen and smart paper in a teaching and learning environment. Different pedagogues explained that every individual differs in how they learn (e.g., [9]), i.e., there are regular differences in individuals' methods used to gain and practice the information in learning.

The use of pen and paper is very crucial for people with a traditional read-write learning style. We can argue that writing can be replaced by typing into the system, but this procedure may not be as much effective for the traditional read-write learners. And the recent research [7] has shown that learning is much more effective when it is done by writing than typing.

The recent development in high-quality digital learning technology has provided one of the most effective tools for driving success in education and learning. McGraw-Hill Education has performed a survey in 2016 and released the findings of 
its Digital Study Trends Survey [16]. According to the study, it is confirmed that a trend is going on that college students are more and more using digital learning technologies and finding it very helpful across all-round activities.

The vast percentage of students is now using digital learning technology for improving their grades (81 percent), to improve the efficiency and effectiveness. Twothirds of students voted that online quizzes and adaptive learning technologies are much more helpful in learning and keeping the contents for longer time period. Students voted that technology improves many aspects of the academic and collegiate experience. More than $80 \%$ of students told that digital learning technology allows them to spend more and more time for study because of increased accessibility, and $63 \%$ of students voted for it make them feel better prepared for the class and provides them better understanding.

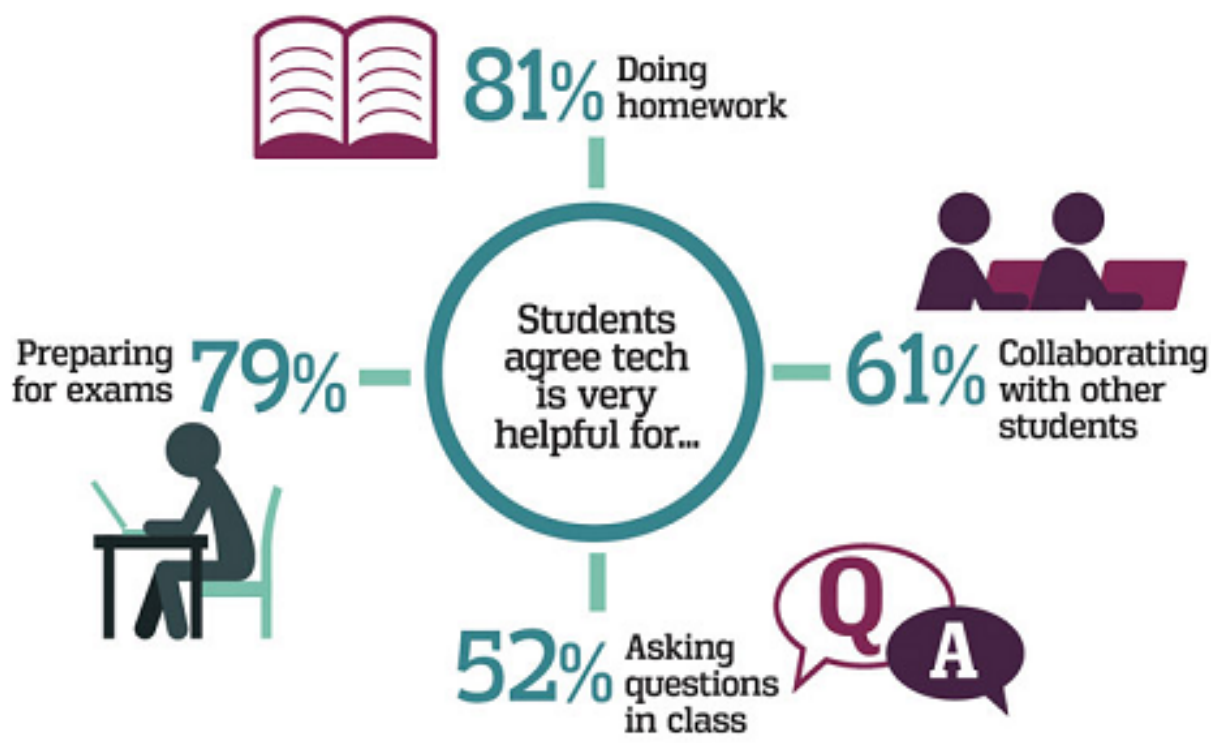

Fig. 1. Education 2016 Digital Study Trends Survey by McGraw-Hill

From all the conclusions it is clear that there is no easy replacement of paper at schools. It looks like paper is something that cannot be easily replaced by smart pen and smart paper or other electronic devices. So, why we can't combine both instead of trying to replace paper by modern technology?

\section{Smart Study Platform}

Smart Study system is an e-learning platform which supports students and children to read, write, solve class room problems and at the same time they are also improving their writing skills. 


\subsection{Smart Study Technologies}

Smart Study system contains smart pen and smart paper as a major component. Smart digital pens are almost same as a normal ballpoint pen. Smart pens use real ink and they write on real paper. The main difference is the digitization of your work. Everything is being converted to digital information.

\section{Smart pen}

A smart pen allows us to write the text in our natural way (i.e. in our own handwriting) as if we are writing anything on a blank piece of paper or on our note books. Smart pens stores the written contents as it is transferred to our display devices. For example "live scribe smart pen".

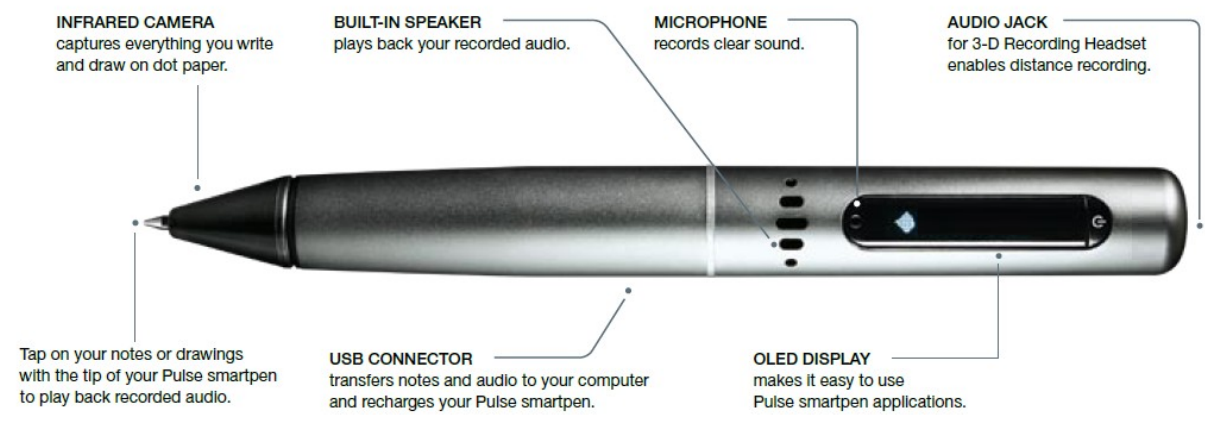

Fig. 2. Smart pen (Source: http://vr-zone.com)

According to toptenreviews.com below are the top five best smart pens [12]:

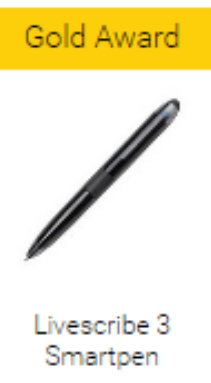

$\$ 189.98$
2

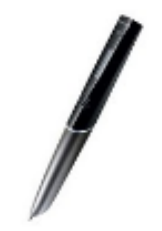

Sky Wifi Smartpen
3

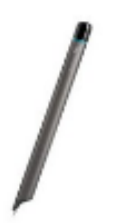

Neo Smartpen N2
4

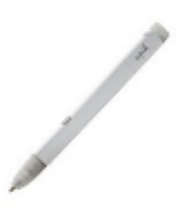

Equil Smartpen 2 $\$ 169.00$
5

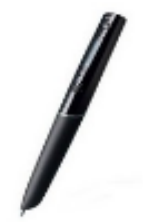

Echo Smartpen

$\$ 113.00$

Fig. 3. Top five smart pens (Source: toptenreviews.com)

Below are the ratings given by toptenreviews.com for top five smart pens based on their performance, features, ease of use and help \& support provided by the manufacturers [12]: 


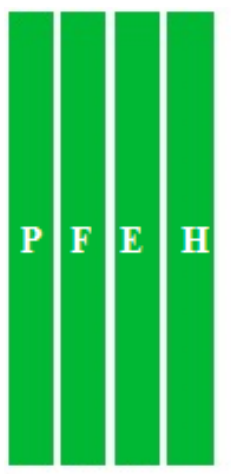

$10.00 / 10$

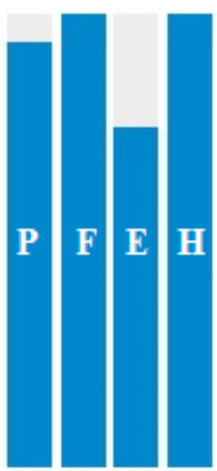

$9.38 / 10$

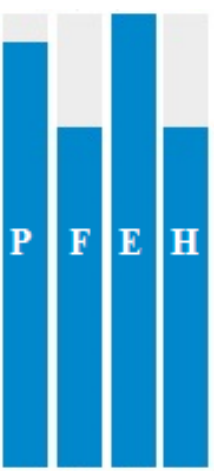

$8.63 / 10$

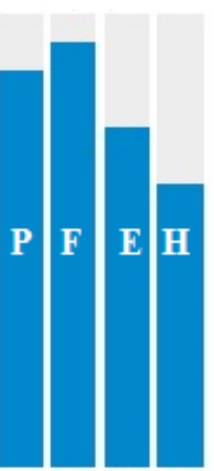

$8.53 / 10$

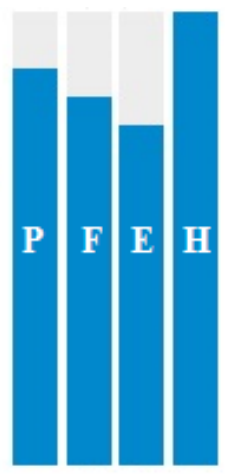

$8.47 / 10$

Legends: $\mathrm{P}=$ Performance $\mathrm{F}=$ Features $\mathrm{E}=$ Ease of Use $\mathrm{H}=$ Help \& Support

Fig. 4. Top five smart pens rating (Source: toptenreviews.com)

Table 1, given below provides the summarized details of different top manufacturers with the ranking and the price in US dollars [12]. In the list Livescribe and Sky Wifi are on 1 st and 2 nd positions respectively.

Table 1. The Best Digital Pens of 2017

\begin{tabular}{|l|l|l|}
\hline \multicolumn{1}{|c|}{ Toptenreviews.com Ranking } & \multicolumn{1}{|c|}{ Digital Pen } & \multicolumn{1}{c|}{ Price USD } \\
\hline 1 & Livescribe 3 Smartpen & 189.98 \\
\hline 2 & Sky Wifi Smartpen & 363.59 \\
\hline 3 & Neo Smartpen N2 & 168.00 \\
\hline 4 & Equil Smartpen 2 & 169.00 \\
\hline 5 & Echo Smartpen & 113.00 \\
\hline 6 & Mobile Notes Pro 2 & 150.75 \\
\hline 7 & Wacom Inkling & 180.00 \\
\hline 8 & IRISNotes 2 Executive & 99.99 \\
\hline 9 & IRISNotes 1 for Smartphones & 114.99 \\
\hline
\end{tabular}

The Smart pen [10] is able to write like a normal ball pen but this pen can capture and record everything whatever is written on smart paper. It uses a tiny digital camera near to the tip of the smart pen. The smart paper is designed in such a manner with dotted pattern [11] and has unique positions, so that the camera in the smart pen can find out the exact location of the tip on the paper.

Smart pen has a small display screen where information can be seen after some actions. There is also a microphone for audio recording purpose, and it has a built-in speaker by which recorded audio can be played. The pen also comes with built-in memory to store whatever has been bagged. Smart pen has a micro-USB connecting port to connect it using a USB cable to transfer data to a computer, laptop or tablet. Smart pen also has Bluetooth and WiFi feature to connect a laptop, smart phone or tablet. 


\section{Smart paper}

Using smart paper, we can capture lectures, seminars, study groups, meetings, and many more events. Each smart notepad pack contains number of sheets of lined dotted paper. Sheets are optimized to use with Livescribe 3 smart pens. These papers are perfect for classes and meetings. The Sky ${ }^{\mathrm{TM}}$, Pulse ${ }^{\mathrm{TM}}$, Echo ${ }^{\mathrm{TM}}$, and the new Livescribe 3 smart pens work only with Livescribe ${ }^{\mathrm{TM}}$ dot papers. This can be used to activate all smart pen applications.

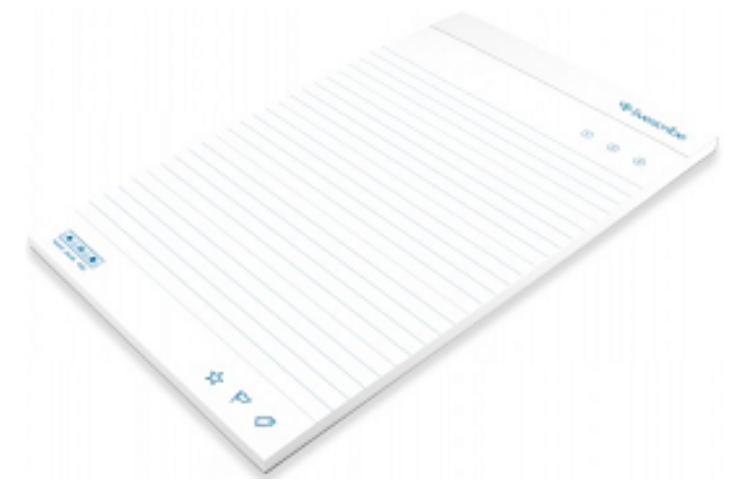

Fig. 5. Smart paper

The idea of the smart paper was around for a few years, but the definition of smart paper continues to shift and grow. A smart paper can be defined as:

Digital: A smart paper can be of a variety of forms, but each and every forms are digital. A smart paper might initially appear very similar to a web page, info graphic or a mobile app. The contents and design of smart paper are hosted online, very much like a web page, with some URL. The smart paper may have a unique domain and or a sub domain. The smart paper can be used for promotions through an email campaigns and through other channels by sharing the link.

Interactive: Smart paper is "smart" because of its interactive feature. At a base level, a smart paper incorporates reader-controlled navigation. The user can easily and quickly skip from one section to another or from one chapter to another chapter by using a well-designed interactive table of contents (TOCs).

It's more responsive, more compatible, simpler to navigate, regardless of device, far more scanable and easier to share through social networks and better for SEO. Livescribe, Moleskine, Evernote Smart Notebook, Mod Notebooks and Walcom's Bamboo Spark are some leading players in the field of smart paper and notebooks.

\section{$4 \quad$ Smart Study System Architecture}

Smart study system contains a smart pen, smart paper, Asp.net and C\# application and MS-SQL server database. Fig. 6 shown below provides idea about the proposed smart study architecture with the major components of the platform: 


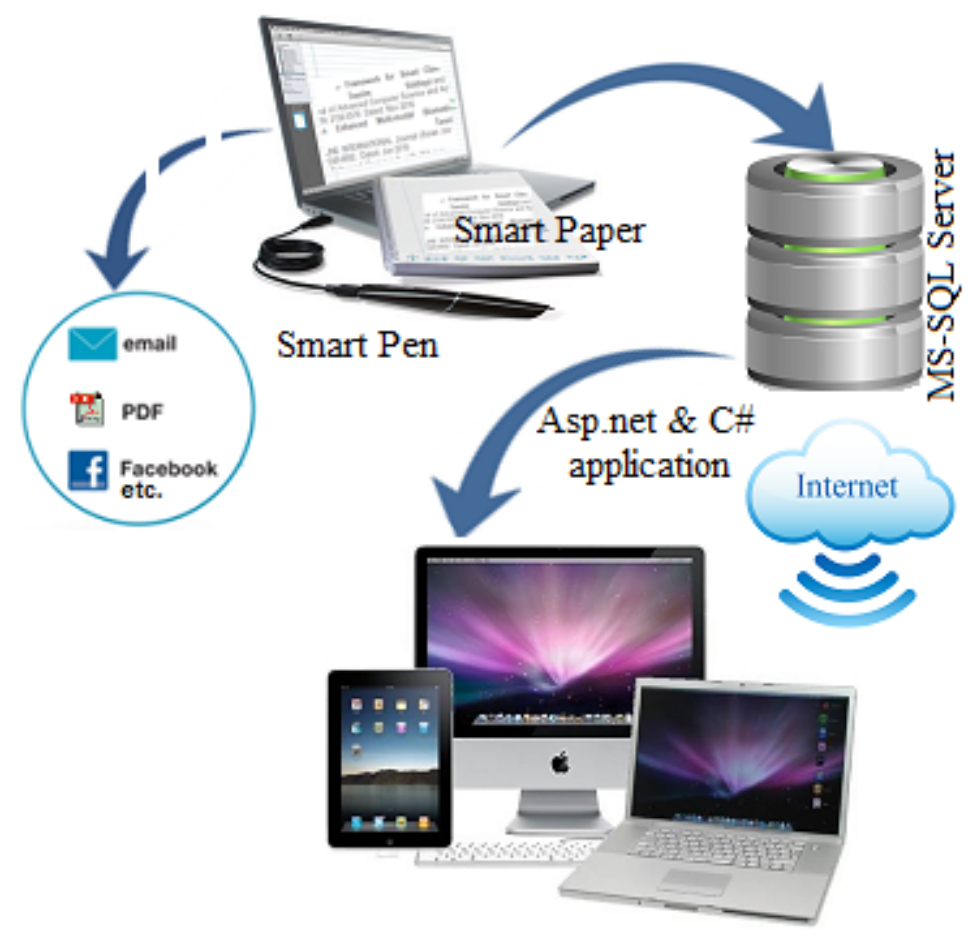

Fig. 6. Proposed Smart Study Architecture

Major components of the system are:

1. Writing: This is to write on smart paper

2. Reading: This is to read the contents using smart pen

3. Data storage: Here we store the data into database

4. Accessing data: We can access the contents from database depending on the requirement.

First thing is to write on the smart paper by using smart pen which has the features of digital capturing, transmission and processing of data and drawings figures on paper. After finishing the writing process, the contents need to be read from the smart paper by using smart pen. Now we need to store the contents into smart pen or transfer them into laptops and tablets etc. From here we can also share the data via email, social media applications and also export them into ".pdf", ".doc" and other file formats. After all these things we have to store data to the MS SQL Server database. To store the data into database we have to connect the smart pen with a micro-USB cable to a laptop or personal computer. We can store the data and later we can retrieve as and when it is required. Final thing is data need to be accessed from the database by using web application and mobile applications. 
Web application is based on .net platform. It includes asp.net for the front end (GUI) design of web pages and C\# for the code behind part. Code behind part contains the core coding of the system.

\subsection{Working of Smart Study System}

Working of proposed smart study architecture can be understood using the steps given below:

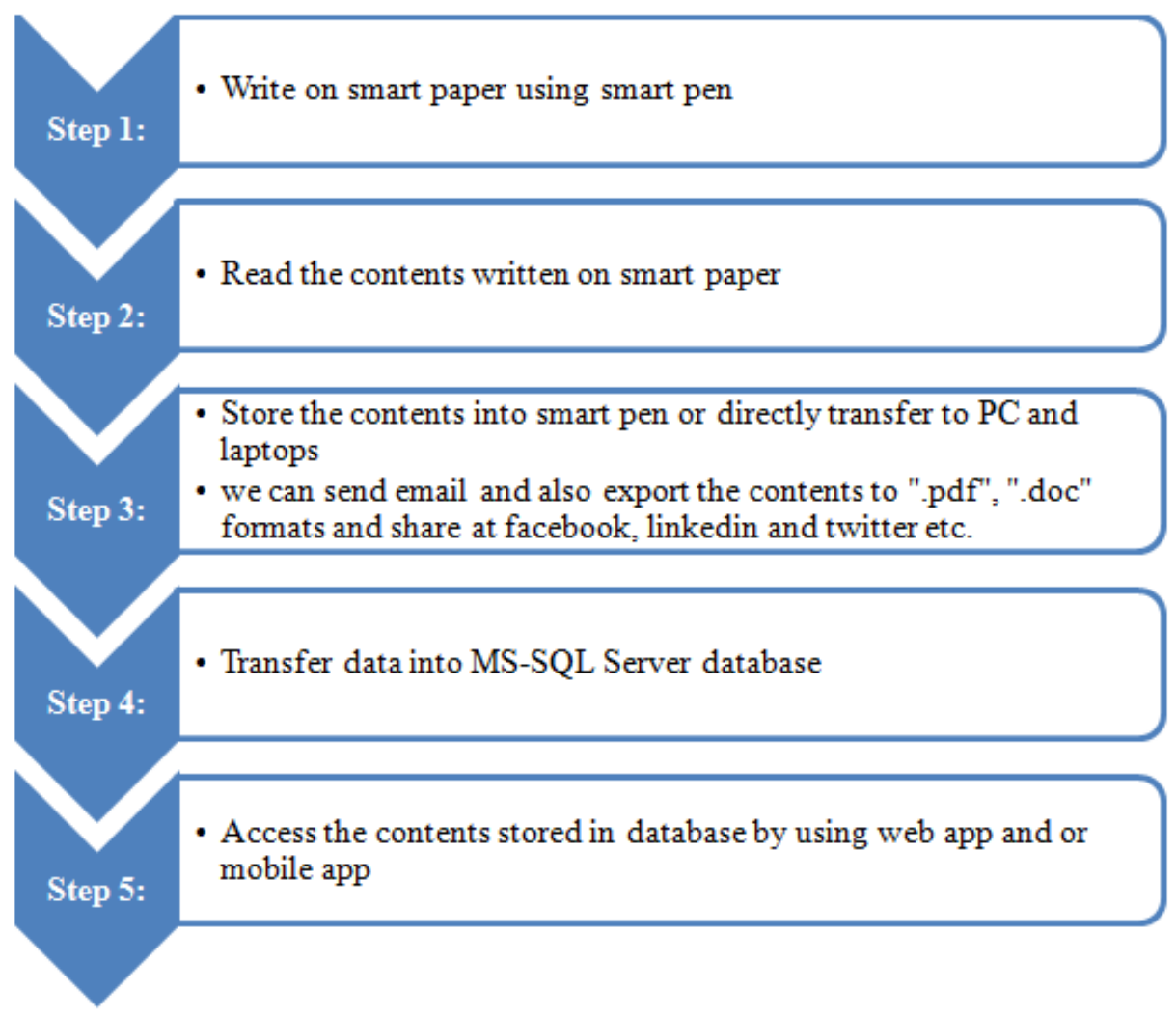

Step 1 is to write on the smart paper by using smart pen which has the features of digital capturing, transmission and processing of data and drawings figures on paper.

In step 2, the contents are being read from the smart paper by using smart pen.

Step 3 is all about the storing the contents into smart pen or transferring them into computer. We can also share the data via email, social media applications and also export to .pdf, .doc and other file formats.

Step 4 is all about transferring and storing data to the MS SQL Server database. Data transfer can be done by connecting the smart pen with a micro-USB cable to a laptop or computer. We can store the data and later we can retrieve as required. 
In step5 data is being accessed from the database by using web application and mobile applications.

\section{Conclusion}

This paper proposes the Smart Study architecture. Smart Study is a platform that combines the use of smart pen and smart paper. Using smart paper and pen the contents written on the paper can be converted into digital contents. Smart study using pen and paper is helpful for practicing handwriting in same traditional manner. The contents can be stored and transferred as well as can be exported into the different formats e.g. pdf and doc etc. they can also be shared and sent via email. It allows learners continue their learning in smart way. With the advancement in technology, it can be improved with the features like direct transfer of contents while writing, to the computer and other devices in future.

\section{References}

[1] LeapFrog: Leapfrog. http://www.leapfrog.com

[2] Berque, D., Bonebright, T., Whitesell, M.: Using pen-based computers across the computer science curriculum. In: ACM SIGCSE Bulletin, vol. 36, pp. 61-65. ACM (2004)

[3] Miura, M., Kunifuji, S., Shizuki, B., Tanaka, J.: Airtransnote: augmented class- rooms with digital pen devices and rfid tags. In: IEEE International Workshop on Wireless and Mobile Technologies in Education 2005 (WMTE 2005), pp. 56-58. IEEE (2005)

[4] Sugihara, T., Miura, T., Miura, M., Kunifuji, S.: Examining the effects of the simultaneous display of students' responses using a digital pen system on class activity-a case study of an early elementary school in Japan. In: 2010 IEEE 10th International Conference on Advanced Learning Technologies (ICALT), pp. 294-296. IEEE (2010)

[5] Miura, M., Sugihara, T., Kunifuji, S.: Improvement of digital pen learning system for daily use in classrooms. Educ. Technol. Res. 34, 49-57 (2011)Google Scholar

[6] Sellen, A., Harper, R.: The Myth of the Paperless Office. MIT Press (2003)

[7] Mueller, P.A., Oppenheimer, D.M.: The pen is mightier than the keyboard advantages of longhand over 7 laptop note taking. Psychological science, p. 0956797614524581 (2014)

[8] Ozok, A.A., Benson, D., Chakraborty, J., Norcio, A.F.: A comparative study between tablet and laptop pcs: user satisfaction and preferences. Int. J. Hum.-Comput. Interact. 24(3), 329-352 (2008)CrossRefGoogle Scholar https://doi.org/10.1080/10447310801920524

[9] James, W.B., Gardner, D.L.: Learning styles: implications for distance learning. New Dir. Adult Continuing Educ. 1995(67), 19-31 (1995) CrossRef Google Scholar https://doi.org/10.1002/ace.36719956705

[10] Livescribe: Echo smartpen. http://www.livescribe.com/en-us/smartpen/echo/

[11] Anoto: The Pattern. http://www2.anoto.com/the-paper-3.aspx (2014)

[12] http://www.toptenreviews.com/electronics/family/best-digital-pens/

[13] Ana Belén Lago Vilariño and Iván Pretel García. An E-Learning Platform for Integrated Management of Documents Based on Automatic Digitization.

[14] Da Silva \& Da Rocha. InkBlog: A Pen-Based Blog Tool for e-Learning Environments

[15] Benlloch, J., Buendía, F., \& Cano, J. (2009, July). Tablet PC-based learning approach on a first-year computer engineering course. Proceedings of the 9th IEEE International Confer- 
Paper-An Approach to Smart Study using Pen and Paper Learning

ence on Advanced Learning Technologies, Riga, Latvia, 86-87. doi: 10.1109/ICALT.2009.155 https://doi.org/10.1109/ICALT.2009.155

[16] http://www.mheducation.com/ideas/digital-study-success.html

\section{$7 \quad$ Authors}

Ahmad Tasnim Siddiqui is member of the Institute of Electrical and Electronics Engineers (IEEE), and Association for Computing Machinery (ACM). He is lecturer in Department of Computer Science at Taif University, Taif, Saudi Arabia. He is also the member and technical member in few journals.

Mohd. Muntjir is member of the Institute of Electrical and Electronics Engineers (IEEE). He is lecturer in Department of Information Technology at Taif University, Taif, Saudi Arabia.

Article submitted 23 February 2017. Published as resubmitted by the authors 15 April 2017. 